\title{
Synergic effect of diabetes mellitus and $H$. pylori infection on proliferation of cells via downregulating the expression of PTEN by hypermethylating its promoter region
}

\section{Huibin Lu}

The First Affiliated Hospital of Zhengzhou University

Xinwei Han ( $\nabla$ docablation@yeah.net)

The First Affiliated Hospital of Zhengzhou University https://orcid.org/0000-0003-1051-0242

Jianzhuang Ren

The First Affiliated Hospital of Zhengzhou Universityl

\section{Kewei Ren}

The First Affiliated Hospital of Zhengzhou University

\section{Zongming Li}

The First Affiliated Hospital of Zhengzhou University

Quanhui Zhang

The First Affiliated of Zhengzhou University

\section{Primary research}

Keywords: GC, DM, PTEN, Metformin, Methylation, H. pylori

Posted Date: April 7th, 2020

DOI: https://doi.org/10.21203/rs.3.rs-20761/v1

License: (c) (i) This work is licensed under a Creative Commons Attribution 4.0 International License.

Read Full License 


\section{Abstract}

Background It has been reported that CagA of $\mathrm{H}$. pylori reduced the expression of PTEN by enhancing its promoter methylation. Furthermore, DM may also promote the methylation status of PTEN, a tumor suppressor gene in Gastric cancer. It is intriguing to explore whether DM may strengthen the tumorigenic effect of HP by promoting the methylation of PTEN promoter and whether the administration of metformin may reduce the risk of GC by suppressing the methylation of PTEN promoter.

Methods Bisulfite sequencing PCR was performed to measure the DNA methylation of PTEN promoter in GC patients and HGC-27 cells treated under different conditions. Quantitative real-time PCR was carried out to measure the expression of PTEN mRNA. Immunohistochemistry and Western blot were used to evaluate the expression of PTEN protein. Immunofluorescence and flow cytometry were performed to analyze the apoptosis of GC tissue samples and HGC-27 cells treated under different conditions. MTT assay was carried out to examine the proliferation of HGC-27 cells.

Results DNA methylation of PTEN promoter was synergetic enhanced by HP infection and Diabetes mellitus in patients with Gastric cancer. Accordingly, the expression of PTEN was suppressed in GC patients with HP infection and DM. Furthermore, cell apoptosis was decreased in GC patients with HP infection and DM. Metformin showed an apparent effect on maintaining CagA induced elevation of PTEN promoter methylation, thus attenuating the PTEN expression, increasing the proliferation and suppressing the apoptosis of HGC-27 cells.

Conclusion In this study, we collected GC tumor tissues from GC patients with or without DM/HP to compare their PTEN methylation and expression while testing the effect of Metformin on the methylation of PTEN promoter. Our study provided evidence for the mechanism underlying the therapeutic role of Metformin in GC treatment.

\section{Background}

Gastric cancer (GC) is one of highly frequently diagnosed cancers in the world. GC causes the 2 nd highest death rate among all types of cancers. The majority of GC cases are actually gastric carcinoma and gastric antrum cancer, although the occurrence of carcinoma at gastroesophageal junction has actually been rising steadily [1-3]. Review of the onset of GC showed that the occurrence of GC is slowly increasing among youth adults as well as in children. Also, the occurrence, death rate, as well as metastasis of GC are pretty high, along with low rate of early diagnosis, good prognosis, as well as 5 year survival [4].

The gene of phosphatase and Tensin homologue on chromosome 10 (PTEN) is deemed as a possible tumor suppressor in numerous forms of cancers in human [5]. PTEN is likely to suppress phosphatidylinositol-3-kinase (PI3K) expression through catalyzing the elimination of D3 phosphate from phosphatidylinositol $(3,4,5)$ - triphosphate (PIP3) to dysregulate the production of phosphatidylinositol 4,5-bisphosphate (PIP2) as well as PIP3 [6-8]. PTEN is actually downregulated in GC, and the expression 
of PTEN is also negatively correlated to metastasis in lymph nodes, depth of invasion, as well as the age of GC patients [9-11]. PTEN was shown to suppress the cell cycle arrest, apoptosis, as well as metastasis of GC cells $[12,13]$. Formerly, Tet1 has actually been shown to prevent the metastasis as well as development of GC through PTEN demethylation as well as its expression. Tet1 reduces the migration, development, as well as invasion of $\mathrm{GC}$ through the demethylation of $\mathrm{CpG}$ islands in the promoter region of PTEN, thus downregulating focal adhesion kinase as well as AKT activity [14].

The role of DM in the risk of cancer has been analyzed in various meta analyses [15]. Epidemiologic research reviewing the relationship between $\mathrm{DM}$ and the risk of $\mathrm{GC}$ has generated contradictory results $[16,17]$. It was shown that PTEN promoter hypomethylation is actually quite common among Uyghur patients carrying wild type T2DM, which might contribute to T2DM pathogenesis. The abnormal methylation of $\mathrm{CpG}$ sites in the promoter of PTEN might function as a biomarker for T2DM diagnosis.

Helicobacter pylori are a global threat that has infected about 4 billion individuals [18]. Helicobacter pylori are actually the primary reason for peptic ulcer disease, gastritis, as well as GC. Previous research has actually revealed that the infection by helicobacter pylori caused an epithelial-to-mesenchymal transition of epithelial cells in the stomach [19]. It was revealed that CagA considerably lowered the PTEN as well as Tet 1 expression. Furthermore, it was uncovered that CagA lowered PTEN expression through enhancing its own methylation, which was actually dramatically decreased by Tet1 [20]. Metformin is a compound extracted from Galega officinalis and has actually been utilized for years in medical treatment to type 2 diabetes mellitus (T2DM) [21]. It was shown that metformin dramatically reduces AKTdependent phosphorylation [22].

CagA of H. pylori reduces the expression of PTEN by enhancing its promoter methylation [20]. Furthermore, DM may also promote PTEN methylation [23]. Giving the fact that DM and HP infection may synergistically elevate the risk of GC as well as the ability of metformin to suppress the methylation of PTEN, we hypothesized that DM may strengthen the tumorigenic effect of HP by promoting PTEN promoter methylation, and the administration of metformin may reduce the risk of GC by suppressing PTEN promoter methylation [23-25]. In this study, we collected GC tumor tissues from GC patients with or without DM/HP to compare their PTEN methylation and expression while testing the effect of Metformin on the methylation of PTEN promoter.

\section{Materials And Methods}

\section{Human subjects sample collection}

In this study, we enrolled 107 patients with gastric cancer and divided them into three groups according to their status of HP (H. Pylori) infection and Diabetes mellitus, i.e., 1. HP(-) DM(-) group ( $=39)$, 2. $\mathrm{HP}(+)$ $\mathrm{DM}(-)$ group, $(\mathrm{N}=32)$, and 3. $\mathrm{HP}(+) \mathrm{DM}(+)$ group, $(\mathrm{N}=36)$. The information of participants, including their age, gender, smoking history, drinking history, staging of gastric cancer, location of gastric cancer, was 
collected and compared among different groups. Institutional ethical committee has approved the protocol of this study.

\section{Bisulfite Sequencing}

We used bisulfite sequencing to determine the level of DNA methylation in the promoter of the PTEN gene. In brief, genomic DNA in the samples was isolated by making use of a QIAamp DNA Mini assay kit (Qiagen, Hiden, Germany) in accordance with the routine assay protocol provided by the kit manufacturer. Then, Bisulfite conversion was carried out via adding $5 \mathrm{M}$ of salt sodium bisulfite to each $1.8 \mu \mathrm{g}$ of the DNA sample. A universal primer free of $\mathrm{CpG}$ was made use of for the amplification of both demethylated as well as methylated promoter of the PTEN gene at $55.0^{\circ} \mathrm{C}$ annealing temperature. The product of PCR was then quantitatively evaluated through using DHPLC on a WAVE DNA Fragment Analysis System in accordance with the routine assay protocol provided by the manufacturer.

\section{Rna Isolation And Real-time Pcr}

Real time PCR was done to measure the expression of PTEN and CagA mRNA in collected samples. In brief, total RNA in each sample was isolated by utilizing a PureLink RNA Mini assay kit (Thermo Fisher Scientific, Waltham, MA) in accordance with the routine assay protocol provided by the kit manufacturer. Then, cDNA was generated from isolated total RNA by making use of a PrimeScript RT Reagent assay kit (Thermo Fisher Scientific, Waltham, MA) in accordance with the routine assay protocol provided by the kit manufacturer. In the next step, the real time PCR was carried out on an iCycler real time PCR instrument (Bio-Rad Laboratories, Hercules, CA) by utilizing an iQSYBR Green master kit (Bio-Rad Laboratories, Hercules, CA) in accordance with the routine assay protocol provided by the kit manufacturer. The $\Delta \Delta \mathrm{Ct}$ method was used to determine the relative expression of PTEN and CagA mRNA in each sample, with housekeeping gene GAPDH serving as the internal reference.

\section{Cell Culture And Transfection}

HGC-27 cells were bought from American Type Culture Collection (ATCC, Manassas, VA) and maintained in an RPMI 1640 medium (Gibco, Thermo Fisher Scientific, Waltham, MA) added with $10 \%$ of fetal bovine serum (Gibco, Thermo Fisher Scientific, Waltham, MA) as well as a suitable amount of penicillin and streptomycin (Gibco, Thermo Fisher Scientific, Waltham, MA). The culture was carried out at $37^{\circ} \mathrm{C}$ in an incubator containing 5\% CO2. Prior to the experiments, the cells were randomly divided into 4 groups, i.e., 1. Untreated group (HGC-27 cells treated with PBS only); 2. Metformin group (HGC-27 cells treated with 100 uM of Metformin); 3. CagA group (HGC-27 cells treated with CagA); 4. CagA + Metformin group (HGC27 cells treated with CagA and $100 \mathrm{uM}$ of Metformin). After $48 \mathrm{~h}$ of treatment, the cells were collected for subsequent assays. 


\section{Construction Of Recombinant Plasmids And Packaging of Lentiviral Vectors}

HEK 293T cells and HGC 27 cells, a human GC cell line, were bought from American Type Culture Collection (ATCC, Manassas, VA) and maintained in a Dulbecco Modified Eagle's Medium (DMEM, Gibco, Thermo Fisher Scientific, Waltham, MA) added with $10 \%$ of fetal bovine serum (Gibco, Thermo Fisher Scientific, Waltham, MA) as well as a suitable amount of penicillin and streptomycin (Gibco, Thermo Fisher Scientific, Waltham, MA). The culture was carried out at $37^{\circ} \mathrm{C}$ in an incubator containing $5 \% \mathrm{CO} 2$. Then, the catalytic domain of Tet1 was utilized to create 3 shRNAs. After annealing, the shRNAs were incubated with dATP and T4 DNA polymerase, and then inserted into a pds019-pl6.3- SHRNA-BSD vector (EMD Millipore, Billerica, MA). In the next step, the vector was transformed into E. coli and the resulting plasmids were called CL946-3, CL946-2 as well as also CL946-1. Moreover, the catalytic domain of Tet1 was inserted into a PDS087_pL6-TO-V5-GIM vector (EMD Millipore, Billerica, MA) and the resulting plasmid was called CL981_pL6-TO-V5-tet1-CD. In a similar way, a vector overexpressing CagA was produced. Ultimately, an Opti-Mum Essential Medium (MEM, Thermo Fisher Scientific, Waltham, MA) and a packaging reagent (Thermo Fisher Scientific, Waltham, MA) were used with $3 \mu \mathrm{g}$ of the lentiviral plasmid and Lipofectamine 2000 (Invitrogen, Carlsbad, CA) in accordance with the routine assay protocol provided by the kit manufacturer to transfect HEK 293T cells. After $48 \mathrm{~h}$ of transfection, the supernatant of cells was centrifuged for 10 minutes at $1,500 \mathrm{~g}$ and ambient temperature to collect the viral vectors.

\section{MTT cell proliferation assay}

The proliferation status of treated cells was measured by utilizing a CellTiter-Glo MTT assay (Promega, Madison, $\mathrm{WI}$ ) in accordance with the routine assay protocol provided by the kit manufacturer.

\section{Western Blot Analysis}

Collected tissue and cell samples were lysed by using a Trizol reagent (Invitrogen, Carlsbad, CA) in accordance with the routine assay protocol provided by the reagent manufacturer to obtain protein lysate, which was then resolved via electrophoresis by making use of a 10\% SDS-PAGE gel. After transferring the resolved protein samples onto PVDF membranes, the membranes were blocked by making use of $5 \%$ skim milk and then incubated overnight at $4{ }^{\circ} \mathrm{C}$ with anti-PTEN primary antibody (R\&D systems, Minneapolis, MN). In the next step, the membranes were washed and further incubated at room temperature for $1 \mathrm{~h}$ with horseradish peroxidase-labeled secondary antibody. Finally, the relative expression of PTEN protein in each sample was analyzed after the protein blot was developed by making use of an Immobilon Western Chemiluminescent HRP Substrate assay kit (EMD Millipore, Billerica, MA) in accordance with the routine assay protocol provided by the kit manufacturer. 


\section{Apoptosis Analysis}

The status of apoptosis in each collected cell and tissue sample was analyzed by using a propidium iodide/annexin V-FITC apoptosis assay kit (Sigma Aldrich, St. Louis, MO) in accordance with the routine assay protocol provided by the kit manufacturer. The detection of apoptosis was carried out on a FACSCanto II flow cytometer (BD Biosciences, San Jose, CA) at a $488 \mathrm{~nm}$ wavelength.

\section{Immunofluorescence And Immunohistochemistry}

Immunofluorescence and immunohistochemistry assays were used to detect the expression of PTEN and the status of apoptosis of collected tissue samples, respectively. In brief, for immunohistochemistry assays, the tissue samples were fixed by using $4 \%$ of formaldehyde (Sigma Aldrich, St. Louis, MO), deparaffinized, and rehydrated using gradient alcohol. In the next step, the sections were stained with anti-PTEN primary antibody (Abcam, Cambridge, MA) and suitable biotin-labeled secondary antibody (Thermo Fisher Scientific, Waltham, MA) before the relative PTEN expression in each sample was evaluated under a Zeiss LSM700 confocal laser-scanning microscope in accordance with the instruction provided by the manufacturer. For immunofluorescence assays, the status of apoptosis of collected tissue samples was evaluated by using a Vybran Apoptosis Assay Kit (Thermo Fisher Scientific, Waltham, $\mathrm{MA}$ ) in accordance with the routine assay protocol provided by the kit manufacturer.

\section{Statistical analysis}

All statistical evaluations were conducted by making use of GraphPad Prism 8.0 for Microsoft Windows (GraphPad, La Jolla, CA). All data were shown as mean \pm SEM. The difference between two different groups was evaluated by using a two-tailed Student's $t$ test. A p value of $<0.05$ was deemed significant statistically.

\section{Results}

\section{The characteristics of patients}

We enrolled 107 gastric cancer patients and divided them into three groups according to their status of HP (H. Pylori) infection and Diabetes mellitus: 1. HP(-)DM(-) $(\mathrm{N}=39), 2$. $\mathrm{HP}(+) \operatorname{DM}(-)(\mathrm{N}=32), 3$.

$\mathrm{HP}(+) \operatorname{DM}(+)(\mathrm{N}=36)$. The information of participants was collected and listed in Table 1. Student's test was utilized to perform the statistical comparison, and revealed that there was no obvious difference in all above characteristics among the three groups. 
Table 1

Demographic and clinical characteristics of recruited subjects

\begin{tabular}{|c|c|c|c|c|}
\hline Characteristics & $\mathrm{HP}(-) \mathrm{DM}(-)(\mathrm{N}=39)$ & $\mathrm{HP}(+) \operatorname{DM}(-)(\mathrm{N}=32)$ & $\mathrm{HP}(+) \mathrm{DM}(+)(\mathrm{N}=36)$ & $P$ value \\
\hline Age, years & & & & 0.279 \\
\hline$₫ 60$ & $18(46.2)$ & $14(43.8)$ & $18(50.0)$ & \\
\hline$\geq 60$ & $21(53.8)$ & $18(56.2)$ & $18(50.0)$ & \\
\hline Gender & & & & 0.538 \\
\hline Male & $30(76.9)$ & $24(75.0)$ & $31(86.1)$ & \\
\hline Female & $9(23.1)$ & $8(25.0)$ & 5 (13.9) & \\
\hline Smoking & & & & 0.608 \\
\hline Ever or curent & $20(51.3)$ & $18(56.3)$ & $20(55.6)$ & \\
\hline Never & $17(43.6)$ & $13(40.6)$ & $15(41.6)$ & \\
\hline Missing & $2(5.1)$ & $1(3.1)$ & $1(2.8)$ & \\
\hline Drinking & & & & 0.178 \\
\hline Ever or curent & $18(46.2)$ & $17(53.1)$ & $20(55.6)$ & \\
\hline Never & $20(51.2)$ & $14(43.8)$ & $14(38.8)$ & \\
\hline Missing & $1(2.6)$ & $1(3.1)$ & $2(5.6)$ & \\
\hline Stage & & & & 0.376 \\
\hline Early & $15(38.5)$ & $13(40.6)$ & $18(50.0)$ & \\
\hline Advanced & 13 (33.3) & $8(25.0)$ & $8(22.2)$ & \\
\hline Missing & $11(28.2)$ & $11(34.4)$ & $10(27.8)$ & \\
\hline Location & & & & 0.882 \\
\hline Cardia & $11(28.2)$ & $8(25.0)$ & $10(27.8)$ & \\
\hline Non-cardia & $25(64.1)$ & $23(71.9)$ & $25(69.4)$ & \\
\hline Missing & $3(7.7))$ & $1(3.1)$ & $1(2.8)$ & \\
\hline
\end{tabular}

HP infection and Diabetes mellitus synergistically increased the DNA methylation level of PTEN promoter in gastric cancer patients. 
As PTEN expression was reported to be closely related to the pathogenesis of gastric cancer, and DNA methylation level of PTEN promoter is reversely correlated with PTEN expression, we performed bisulfite sequencing PCR to evaluate the DNA methylation status of PTEN promoter in the three groups of gastric cancer patients. As shown in Fig.1, DNA methylation of PTEN promoter was slightly increased in $\mathrm{HP}(+) \mathrm{DM}(-)$ patients when compared with HP(-)DM(-) patients. However, DNA methylation of PTEN promoter was remarkably elevated in $\mathrm{HP}(+) \mathrm{DM}(+)$ patients, indicating that HP infection and Diabetes mellitus showed a synergistic effect on promoting the DNA methylation of PTEN promoter in patients with gastric cancer.

\section{HP infection and Diabetes mellitus suppressed the expression of PTEN mRNA and protein in gastric cancer patients in a synergistic manner.}

It is well known that DNA methylation in the promoter region can repress gene expression. Therefore, we further performed quantitative real time PCR and immunohistochemistry assay to examine the PTEN expression in gastric cancer patients in the above three groups. As expected, the expression of PTEN mRNA (Fig.2) and protein (Fig.3) was obviously repressed in HP(+)DM(-) patients in comparison to that in $\mathrm{HP}(-) \mathrm{DM}(-)$ gastric patients. Moreover, the expression of PTEN mRNA and protein in HP(+)DM(+) gastric cancer patients was more apparently suppressed.

\section{The apoptosis of gastric cancerous tissues was inhibited by HP infection and Diabetes mellitus.}

Furthermore, immunofluorescence was carried out to evaluate the apoptotic status of gastric tissues collected from patients in 1. $\mathrm{HP}(-) \mathrm{DM}(-)(\mathrm{N}=39), 2$. $\mathrm{HP}(+) \mathrm{DM}(-)(\mathrm{N}=32), 3 . \mathrm{HP}(+) \mathrm{DM}(+)(\mathrm{N}=36)$ groups. The proportion of apoptotic gastric tissues was progressively decreased from $\mathrm{HP}(-) \mathrm{DM}(-)$ group to $\mathrm{HP}(+) \mathrm{DM}(-)$ and $\mathrm{HP}(+) \mathrm{DM}(+)$ (Fig.4). These results demonstrated that HP infection and Diabetes mellitus played an antagonistic role in the apoptosis of gastric cancer tissues.

\section{Metformin treatment alleviated CagA induced up-regulation of CagA mRNA expression in HGC-27 cells.}

CagA is a toxic component of HP and was shown to alter the expression of PTEN through regulating the DNA methylation of PTEN promoter. We treated HGC-27 cells with CagA and Metformin, and then performed qPCR to measure the expression of CagA mRNA under different conditions. No obvious change of CagA was observed in HGC-27 cells treated with 100uM Metformin when compared with the control. On the contrary, CagA treatment remarkably increased the expression of CagA in HGC-27 cells. The expression of CagA mRNA in HGC-27 cells was apparently decreased under combined treatment with 
CagA and 100uM Metformin when compared with that in HGC-27 cells treated with CagA alone (Fig.5). These results indicated that Metformin treatment reduced CagA-induced up-regulation of CagA mRNA in HGC-27 cells.

\section{Metformin treatment attenuated CagA-induced increase of DNA methylation of PTEN promoter in HGC-27 cells.}

Bisulfite sequencing PCR was carried out to measure the DNA methylation of PTEN promoter in HGC-27 cells treated under different conditions. We found that DNA methylation of PTEN promoter was obviously elevated in HGC-27 cells treated with CagA when compared with that in the control cells, whereas no obvious difference was observed in Metformin-treated HGC-27 cells. However, the DNA methylation of PTEN promoter in HGC-27 cells enhanced by CagA treatment was effectively reduced by Metformin treatment (Fig.6).

\section{Metformin treatment maintained CagA induced down- regulation of PTEN expression in HGC-27 cells.}

Quantitative real time PCR and Western blot were used to analyze the expression of PTEN mRNA and protein in HGC-27 cells treated under different conditions. The expression of PTEN mRNA (Fig.7A) and protein (Fig.7B) in HGC-27 cells was significantly suppressed by CagA treatment, while Metformin treatment showed no obvious effect on the PTEN mRNA expression in untreated HGC-27 cells. However, Metformin treatment effectively restored CagA induced down-regulation of PTEN mRNA and protein in HGC-27 cells.

\section{Metformin treatment restored CagA induced dysregulation of proliferation and apoptosis of HGC-27 cells.}

Finally, we performed MTT assay and flow cytometry to evaluate the proliferation and apoptosis of HGC27 cells treated under different conditions. CagA treatment notably increased the proliferation of HGC-27 cells. Further treatment with Metformin apparently decreased CagA-induced elevation of HGC-27 cell proliferation (Fig.8A). On the contrary, CagA treatment remarkably suppressed the apoptosis of HGC-27 cells. Metformin treatment effectively maintained CagA-induced decrease of HGC-27 cell apoptosis (Fig.8B).

\section{Discussion}

Metformin is well known for its anti-diabetic role [26]. It was also shown that metformin reduced the risk of cancer in patients with T2DM $[27,28]$. The role of metformin in suppressing the proliferation of GC cells is related to its role in blocking cell cycles, which could explain why metformin decreased tumour 
size in mice with xenograft GC tissues $[29,30]$. It was shown that the use of metformin significantly decreased the risk of infection by helicobacter pylori dose dependently [31]. In this study, we recruited 107 gastric cancer patients and divided them into three groups according to their status of HP infection and $\mathrm{DM}$ to explore the molecular mechanism underlying gastric cancer pathogenesis. We found that HP infection and DM effectively increased the DNA methylation of PTEN promoter in GC patients.

PTEN acts as a crucial mediator in the carcinogenesis of a wide array of cancers [32]. PTEN can degrade the derivatives of PI3K through dephosphorylating position 30 of PIP3 as well as PIP2, subsequently boosting AKT phosphorylation and reducing apoptosis $[33,34]$. It was shown that the methylation of PTEN promoter can be used as a prognostic marker of survival [35]. It was illustrated that GC cells transfected by PTEN-shRNA NC displayed considerably down-regulated expression of PTEN, thus substantially enhancing the expression of b-catenin. In addition, IFC as well as Western blotting results showed that PTEN down-regulation and b-catenin up-regulation in GC tissues triggered the phosphorylation of p-AKT as well as p-GSK-3b in GC tissues. In this study, we carried out qPCR and IHC to measure the expression of PTEN mRNA and protein in GC patients in the three groups. HP infection and DM evidently decreased the expression of PTEN mRNA and protein in GC patients. In addition, we used immunofluorescence assays to analyze the apoptosis of GC tissue samples collected from GC patients in the three groups. HP infection and DM notably attenuated the apoptosis of GC tissue samples.

Helicobacter pylori infection is one of the most significant dangers for stomach cancers [36]. In a research on 114 GC patients, gastric adenocarcinoma was shown as accounting for $90 \%$ in all patients. In helicobacter pylori, the expression of a $120 \mathrm{kD}$ a protein called cytotoxin associated gene A (CagA) was shown to be related to some of the essential features of helicobacter pylori to interact with kinases in host cells to trigger tyrosine phosphorylation [37-39]. So far, 4 distinguish EPIYA motifs have been found, i.e., EPIYA-A to EPIYA-D [40, 41]. It was likewise revealed that CagA dramatically lowered the expression levels of PTEN, APOBEC3A, Tet1, APOBEC3C as well as APOBEC3F in GC tissues. Furthermore, CagA lowered the expression levels of PTEN through boosting its levels of methylation, which was substantially blocked through upregulation of Tet1 [20]. it was additionally found that infection with helicobacter pylori strains positive for CagA expression triggers Akt signaling in the epithelial tissues in the stomach, thus attenuating cell apoptosis while promoting cell survival [42-44]. The activation of Akt is actually a common event in chemotherapy treatment of GC, indicating a significant role of Akt in causing apoptosis resistance $[45,46]$. Previous results presented that etoposide boosted the phosphorylation of Akt while minimizing cell survival via the induction of GC apoptosis [47].

It was actually shown that the abnormal methylation in PTEN promoter was substantially reduced in Uyghur subjects suffering from mild cases of T2DM. It was further shown that the hypomethylation in PTEN promoter was actually pretty common in T2DM subjects, indicating that PTEN might contribute to T2DM pathogenesis among Uyghur people [23]. A previous research illustrated that the enhanced PTEN expression in adipose tissues as well as muscular tissues of T2DM rodents might exert a significant effect on insulin resistance in T2DM [48]. Zhu et al. proposed that PTEN controls the production of extracellular matrix in kidneys through activating Akt while enhancing CTGF in T2DM $[49,50]$. In this 
study, we tested the therapeutic effect of Metformin on HGC-27 cells stimulated by CagA. We found that Metformin treatment could effectively maintain CagA-induced dysregulation of PTEN promoter methylation, PTEN mRNA and protein expression, as well as the proliferation and apoptosis of HGC-27 cells.

\section{Conclusion}

In summary, these findings suggest that the hypermethylation of PTEN promoter is a common event in GC patients with DM and metformin treatment. DM may strengthen the tumorigenic effect of HP by promoting the methylation of PTEN promoter, while the administration of metformin may reduce the risk of GC by suppressing the methylation of PTEN promoter.

\section{Declarations}

\section{Ethics approval and consent to participate}

The Human Research Ethics Committees of The First Affiliated Hospital of Zhengzhou University has approved this research and all methods were performed in accordance with the last vision of the Declaration of Helsinki. Written informed consent was obtained from all patients before the study.

\section{Consent for publication}

Not applicable.

\section{Availability of data and material}

The data that support the findings of this study are available from the corresponding author upon reasonable request.

\section{Competing interests}

The authors declare that they have no competing interests.

\section{Funding}

None

\section{Authors' contributions}

$\mathrm{HL}$ planned the study, $\mathrm{HL}, \mathrm{XH}, \mathrm{JR}$ and $\mathrm{KR}$ collected the data, ZL and QZ collected the literature, XH and JR analyzed the data, $\mathrm{HL}$ and QZ composed the manuscript, and all authors approved the final manuscript.

\section{Acknowledgements}

Not applicable 


\section{References}

$1 \quad$ Frei E, 3rd: Clinical cancer research: an embattled species. Cancer 1982;50:1979-1992.

2 Lee HS, Kim WH, Kwak Y, Koh J, Bae JM, Kim KM, Chang MS, Han HS, Kim JM, Kim HW, Chang HK, Choi YH, Park JY, Gu MJ, Lhee MJ, Kim JY, Kim HS, Cho MY, Gastrointestinal Pathology Study Group of Korean Society of P, Molecular Pathology Study Group of Korean Society of P: Molecular Testing for Gastrointestinal Cancer. J Pathol Transl Med 2017;51:103-121.

3 Li B, Liu HY, Guo SH, Sun P, Gong FM, Jia BQ: Detection of microsatellite instability in gastric cancer and dysplasia tissues. Int J Clin Exp Med 2015;8:21442-21447.

$4 \quad$ Wu H, Wang W, Tong S, Wu C: Nucleostemin regulates proliferation and migration of gastric cancer and correlates with its malignancy. Int J Clin Exp Med 2015;8:17634-17643.

5 Peyrou M, Bourgoin L, Foti M: PTEN in liver diseases and cancer. World J Gastroenterol 2010;16:4627-4633.

6 Perez-Ramirez C, Canadas-Garre M, Molina MA, Faus-Dader MJ, Calleja-Hernandez MA: PTEN and PI3K/AKT in non-small-cell lung cancer. Pharmacogenomics 2015;16:1843-1862.

7 Gupta A, Dey CS: PTEN and SHIP2 regulates PI3K/Akt pathway through focal adhesion kinase. Mol Cell Endocrinol 2009;309:55-62.

8 Li A, Qiu M, Zhou H, Wang T, Guo W: PTEN, Insulin Resistance and Cancer. Curr Pharm Des 2017;23:3667-3676.

9 Fei G, Ebert MP, Mawrin C, Leodolter A, Schmidt N, Dietzmann K, Malfertheiner P: Reduced PTEN expression in gastric cancer and in the gastric mucosa of gastric cancer relatives. Eur $\mathrm{J}$ Gastroenterol Hepatol 2002;14:297-303.

10 Zheng HC, Li YL, Sun JM, Yang XF, Li XH, Jiang WG, Zhang YC, Xin Y: Growth, invasion, metastasis, differentiation, angiogenesis and apoptosis of gastric cancer regulated by expression of PTEN encoding products. World J Gastroenterol 2003;9:1662-1666.

11 Giri D, Ittmann M: Inactivation of the PTEN tumor suppressor gene is associated with increased angiogenesis in clinically localized prostate carcinoma. Hum Pathol 1999;30:419-424.

12 Zheng T, Meng X, Wang J, Chen X, Yin D, Liang Y, Song X, Pan S, Jiang H, Liu L: PTEN- and p53mediated apoptosis and cell cycle arrest by FTY720 in gastric cancer cells and nude mice. J Cell Biochem 2010;111:218-228.

13 Zhang LL, Liu J, Lei S, Zhang J, Zhou W, Yu HG: PTEN inhibits the invasion and metastasis of gastric cancer via downregulation of FAK expression. Cell Signal 2014;26:1011-1020. 
14 Pei YF, Tao R, Li JF, Su LP, Yu BQ, Wu XY, Yan M, Gu QL, Zhu ZG, Liu BY: TET1 inhibits gastric cancer growth and metastasis by PTEN demethylation and re-expression. Oncotarget 2016;7:3132231335.

15 Song S, Wang B, Zhang X, Hao L, Hu X, Li Z, Sun S: Long-Term Diabetes Mellitus Is Associated with an Increased Risk of Pancreatic Cancer: A Meta-Analysis. PLoS One 2015;10:e0134321.

16 Knight A, Askling J, Ekbom A: Cancer incidence in a population-based cohort of patients with Wegener's granulomatosis. Int J Cancer 2002;100:82-85.

17 Jee SH, Ohrr H, Sull JW, Yun JE, Ji M, Samet JM: Fasting serum glucose level and cancer risk in Korean men and women. JAMA 2005;293:194-202.

18 Hooi JKY, Lai WY, Ng WK, Suen MMY, Underwood FE, Tanyingoh D, Malfertheiner P, Graham DY, Wong VWS, Wu JCY, Chan FKL, Sung JJY, Kaplan GG, Ng SC: Global Prevalence of Helicobacter pylori Infection: Systematic Review and Meta-Analysis. Gastroenterology 2017;153:420-429.

19 Bessede E, Staedel C, Acuna Amador LA, Nguyen PH, Chambonnier L, Hatakeyama M, Belleannee G, Megraud F, Varon C: Helicobacter pylori generates cells with cancer stem cell properties via epithelialmesenchymal transition-like changes. Oncogene 2014;33:4123-4131.

20 Zhang B, Zhang X, Jin M, Hu L, Zang M, Qiu W, Wang S, Liu B, Liu S, Guo D: CagA increases DNA methylation and decreases PTEN expression in human gastric cancer. Mol Med Rep 2019;19:309-319.

21 Wahdan-Alaswad RS, Cochrane DR, Spoelstra NS, Howe EN, Edgerton SM, Anderson SM, Thor AD, Richer JK: Metformin-induced killing of triple-negative breast cancer cells is mediated by reduction in fatty acid synthase via miRNA-193b. Horm Cancer 2014;5:374-389.

22 Luo M, Tan X, Mu L, Luo Y, Li R, Deng X, Chen N, Ren M, Li Y, Wang L, Wu J, Wan Q: MiRNA-21 mediates the antiangiogenic activity of metformin through targeting PTEN and SMAD7 expression and PI3K/AKT pathway. Sci Rep 2017;7:43427.

23 Yin L, Cai WJ, Chang XY, Li J, Zhu LY, Su XH, Yu XF, Sun K: Analysis of PTEN expression and promoter methylation in Uyghur patients with mild type 2 diabetes mellitus. Medicine (Baltimore) 2018;97:e13513.

24 Ataseven H, Demir M, Gen R: Effect of sequential treatment as a first-line therapy for Helicobacter pylori eradication in patients with diabetes mellitus. South Med J 2010;103:988-992.

25 Hosseininasab Nodoushan SA, Nabavi A: The Interaction of Helicobacter pylori Infection and Type 2 Diabetes Mellitus. Adv Biomed Res 2019;8:15.

26 Zhou G, Myers R, Li Y, Chen Y, Shen X, Fenyk-Melody J, Wu M, Ventre J, Doebber T, Fujii N, Musi N, Hirshman MF, Goodyear LJ, Moller DE: Role of AMP-activated protein kinase in mechanism of metformin 
action. J Clin Invest 2001;108:1167-1174.

27 Decensi A, Puntoni M, Goodwin P, Cazzaniga M, Gennari A, Bonanni B, Gandini S: Metformin and cancer risk in diabetic patients: a systematic review and meta-analysis. Cancer Prev Res (Phila) 2010;3:1451-1461.

28 Tseng $\mathrm{CH}$ : Metformin and risk of hepatocellular carcinoma in patients with type 2 diabetes. Liver Int 2018;38:2018-2027.

29 Kato K, Gong J, Iwama H, Kitanaka A, Tani J, Miyoshi H, Nomura K, Mimura S, Kobayashi M, Aritomo Y, Kobara H, Mori H, Himoto T, Okano K, Suzuki Y, Murao K, Masaki T: The antidiabetic drug metformin inhibits gastric cancer cell proliferation in vitro and in vivo. Mol Cancer Ther 2012;11:549-560.

30 Nguyen PH, Giraud J, Chambonnier L, Dubus P, Wittkop L, Belleannee G, Collet D, Soubeyran I, Evrard S, Rousseau B, Senant-Dugot N, Megraud F, Mazurier F, Varon C: Characterization of Biomarkers of Tumorigenic and Chemoresistant Cancer Stem Cells in Human Gastric Carcinoma. Clin Cancer Res 2017;23:1586-1597.

31 Fox JG, Li X, Cahill RJ, Andrutis K, Rustgi AK, Odze R, Wang TC: Hypertrophic gastropathy in Helicobacter felis-infected wild-type C57BL/6 mice and p53 hemizygous transgenic mice. Gastroenterology 1996;110:155-166.

32 Keniry M, Parsons R: The role of PTEN signaling perturbations in cancer and in targeted therapy. Oncogene 2008;27:5477-5485.

33 Simpson L, Parsons R: PTEN: life as a tumor suppressor. Exp Cell Res 2001;264:29-41.

34 Curtin JA, Fridlyand J, Kageshita T, Patel HN, Busam KJ, Kutzner H, Cho KH, Aiba S, Brocker EB, LeBoit PE, Pinkel D, Bastian BC: Distinct sets of genetic alterations in melanoma. N Engl J Med 2005;353:2135-2147.

35 Lahtz C, Stranzenbach R, Fiedler E, Helmbold P, Dammann RH: Methylation of PTEN as a prognostic factor in malignant melanoma of the skin. J Invest Dermatol 2010;130:620-622.

36 Noto JM, Peek RM, Jr.: Helicobacter pylori: an overview. Methods Mol Biol 2012;921:7-10.

37 Elzouki AN, Buhjab SI, Alkialani A, Habel S, Sasco AJ: Gastric cancer and Helicobacter pylori infection in the eastern Libya: a descriptive epidemiological study. Arab J Gastroenterol 2012;13:85-88.

38 Covacci A, Censini S, Bugnoli M, Petracca R, Burroni D, Macchia G, Massone A, Papini E, Xiang Z, Figura $\mathrm{N}$, et al.: Molecular characterization of the 128-kDa immunodominant antigen of Helicobacter pylori associated with cytotoxicity and duodenal ulcer. Proc Natl Acad Sci U S A 1993;90:5791-5795. 
39 Tummuru MK, Cover TL, Blaser MJ: Cloning and expression of a high-molecular-mass major antigen of Helicobacter pylori: evidence of linkage to cytotoxin production. Infect Immun 1993;61:17991809.

40 Hatakeyama M: SagA of CagA in Helicobacter pylori pathogenesis. Curr Opin Microbiol 2008;11:30-37.

41 Backert S, Tegtmeyer N, Selbach M: The versatility of Helicobacter pylori CagA effector protein functions: The master key hypothesis. Helicobacter 2010;15:163-176.

42 Tabassam FH, Graham DY, Yamaoka Y: Helicobacter pylori activate epidermal growth factor receptor- and phosphatidylinositol 3-OH kinase-dependent Akt and glycogen synthase kinase 3beta phosphorylation. Cell Microbiol 2009;11:70-82.

43 Yoon JH, Seo HS, Choi SS, Chae HS, Choi WS, Kim O, Ashktorab H, Smoot DT, Nam SW, Lee JY, Park WS: Gastrokine 1 inhibits the carcinogenic potentials of Helicobacter pylori CagA. Carcinogenesis 2014;35:2619-2629.

44 Zaidi SF, Refaat A, Zhou Y, Sualeh Muhammad J, Shin MS, Saiki I, Sakurai H, Sugiyama T: Helicobacter pylori Induces Serine Phosphorylation of EGFR via Novel TAK1-p38 Activation Pathway in an HB-EGF-Independent Manner. Helicobacter 2015;20:381-389.

45 Clark AS, West K, Streicher S, Dennis PA: Constitutive and inducible Akt activity promotes resistance to chemotherapy, trastuzumab, or tamoxifen in breast cancer cells. Mol Cancer Ther 2002;1:707-717.

46 Kraus AC, Ferber I, Bachmann SO, Specht H, Wimmel A, Gross MW, Schlegel J, Suske G, Schuermann M: In vitro chemo- and radio-resistance in small cell lung cancer correlates with cell adhesion and constitutive activation of AKT and MAP kinase pathways. Oncogene 2002;21:8683-8695.

47 Lan KH, Lee WP, Wang YS, Liao SX, Lan KH: Helicobacter pylori CagA protein activates Akt and attenuates chemotherapeutics-induced apoptosis in gastric cancer cells. Oncotarget 2017;8:113460113471.

48 Su D, Zhang CL, Gao YC, Liu XY, Li CP, Huangfu J, Xiao R: Gene Expression and Correlation of Pten and Fabp4 in Liver, Muscle, and Adipose Tissues of Type 2 Diabetes Rats. Med Sci Monit 2015;21:36163621.

49 Zhu L, Zhao S, Liu S, Liu Q, Li F, Hao J: PTEN Regulates Renal Extracellular Matrix Deposit via Increased CTGF in Diabetes Mellitus. J Cell Biochem 2016;117:1187-1198.

50 Li YY, Xiao R, Li CP, Huangfu J, Mao JF: Increased plasma levels of FABP4 and PTEN is associated with more severe insulin resistance in women with gestational diabetes mellitus. Med Sci Monit 2015;21:426-431. 
Figures

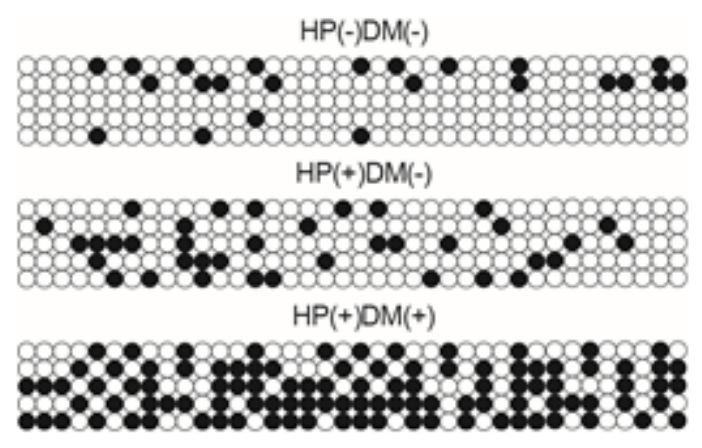

Figure 1

Bisulfite sequencing PCR analysis showed increased DNA methylation of PTEN promoter in HP(-)DM(-) $(\mathrm{N}=39), \mathrm{HP}(+) \operatorname{DM}(-)(\mathrm{N}=32)$ and $\mathrm{HP}(+) \operatorname{DM}(+)(\mathrm{N}=36) \mathrm{GC}$ patients.

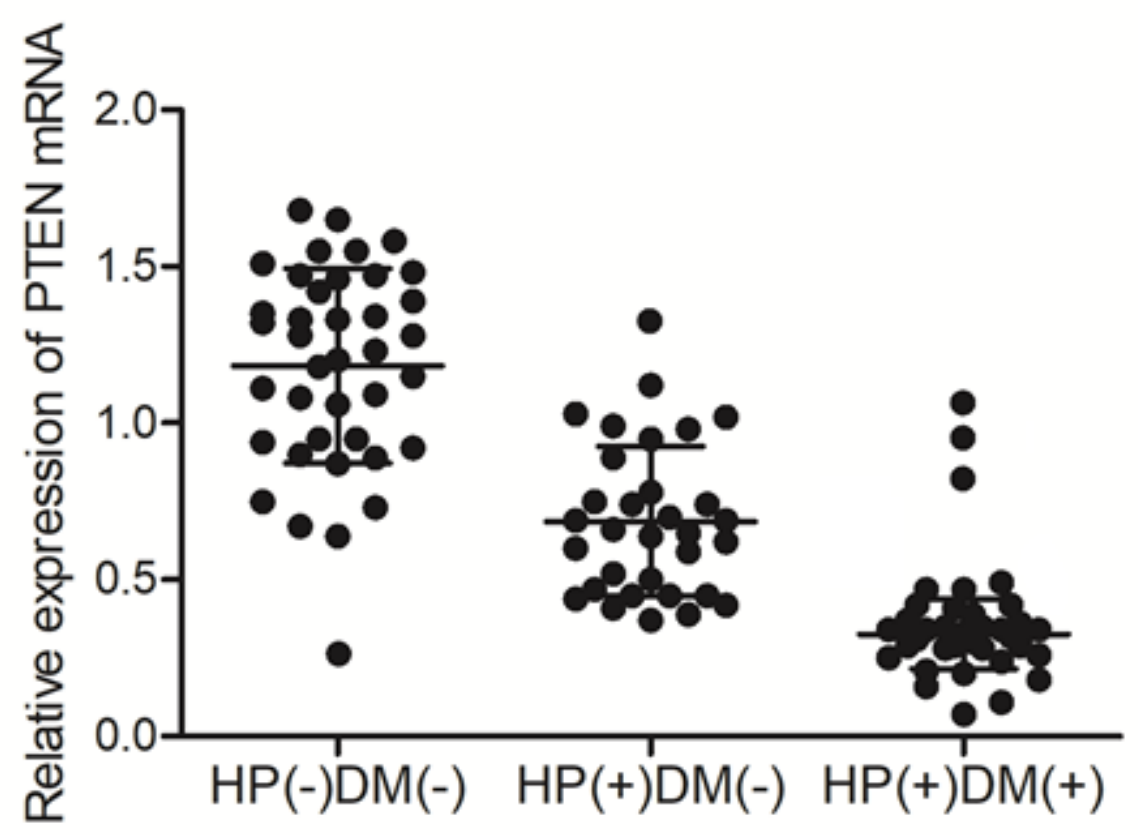

Figure 2

Decreased expression of PTEN mRNA in $\mathrm{HP}(-) \operatorname{DM}(-)(\mathrm{N}=39), \mathrm{HP}(+) \operatorname{DM}(-)(\mathrm{N}=32)$ and $\mathrm{HP}(+) \operatorname{DM}(+)(\mathrm{N}=36)$ GC patients. 


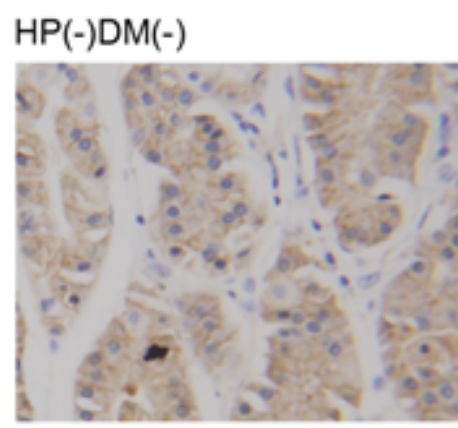

$\mathrm{HP}(+) \mathrm{DM}(-)$

$\mathrm{HP}(+) \mathrm{DM}(+)$
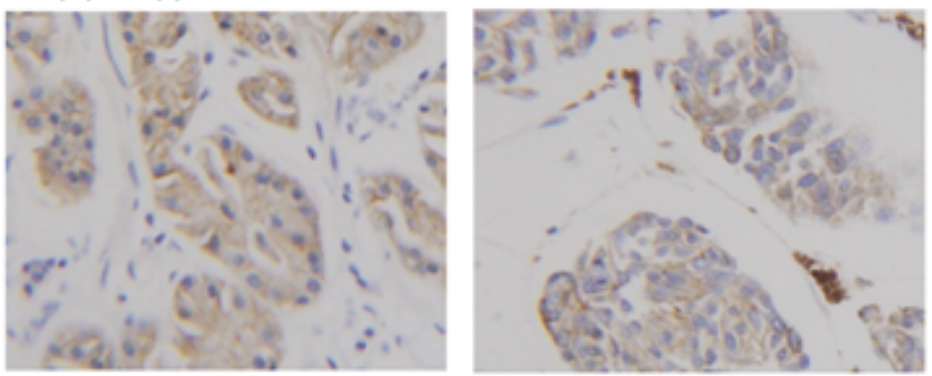

Figure 3

Decreased expression of PTEN protein in $\mathrm{HP}(-) \mathrm{DM}(-)(\mathrm{N}=39), \mathrm{HP}(+) \operatorname{DM}(-)(\mathrm{N}=32)$ and $\mathrm{HP}(+) \mathrm{DM}(+)(\mathrm{N}=36)$ GC patients. 


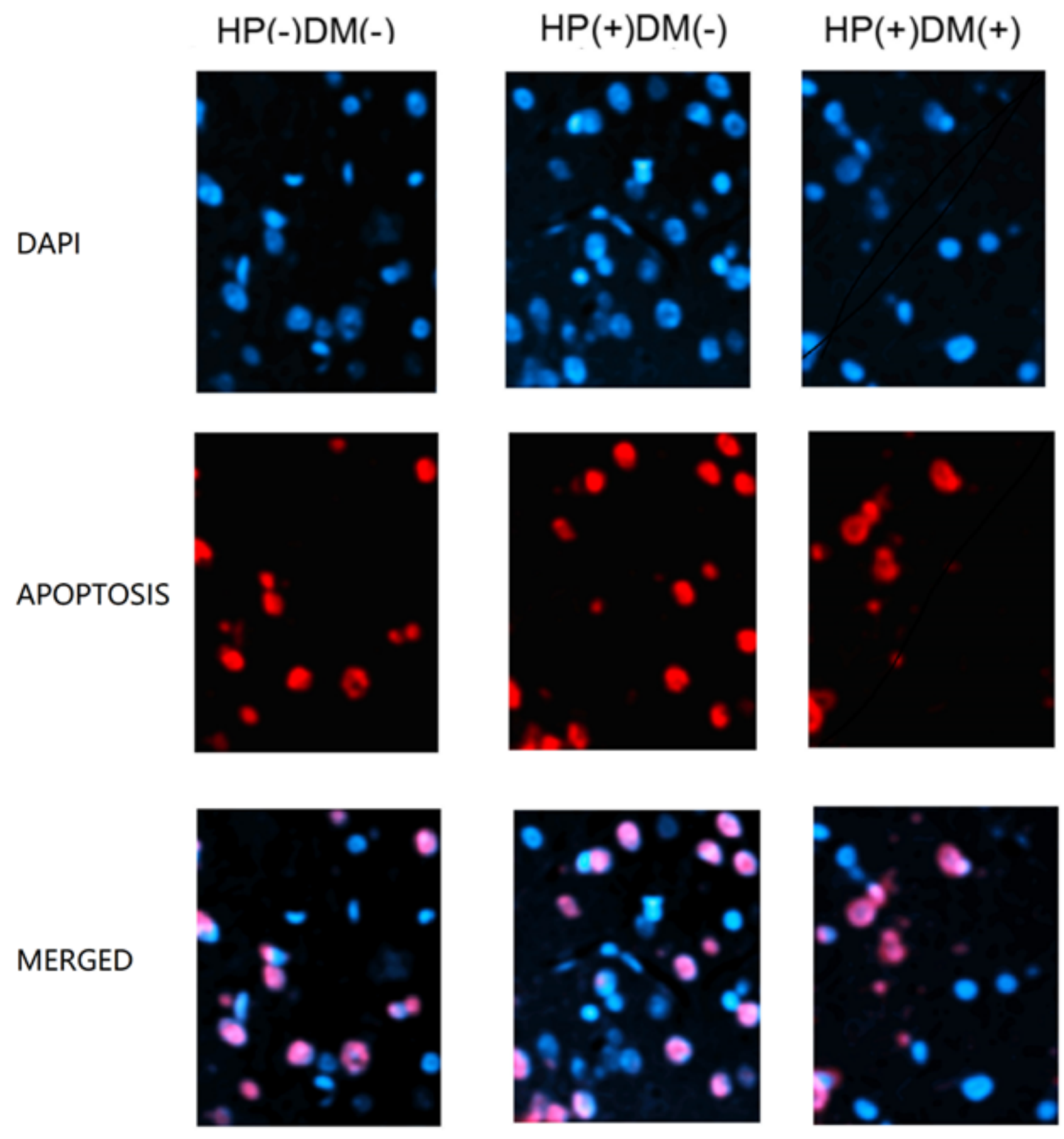

Figure 4

Immunofluorescence analysis showed that the apoptosis of gastric tissues was decreased in $\mathrm{HP}(-) \mathrm{DM}(-)$ $(\mathrm{N}=39), \mathrm{HP}(+) \operatorname{DM}(-)(\mathrm{N}=32)$ and $\mathrm{HP}(+) \mathrm{DM}(+)(\mathrm{N}=36) \mathrm{GC}$ patients. 


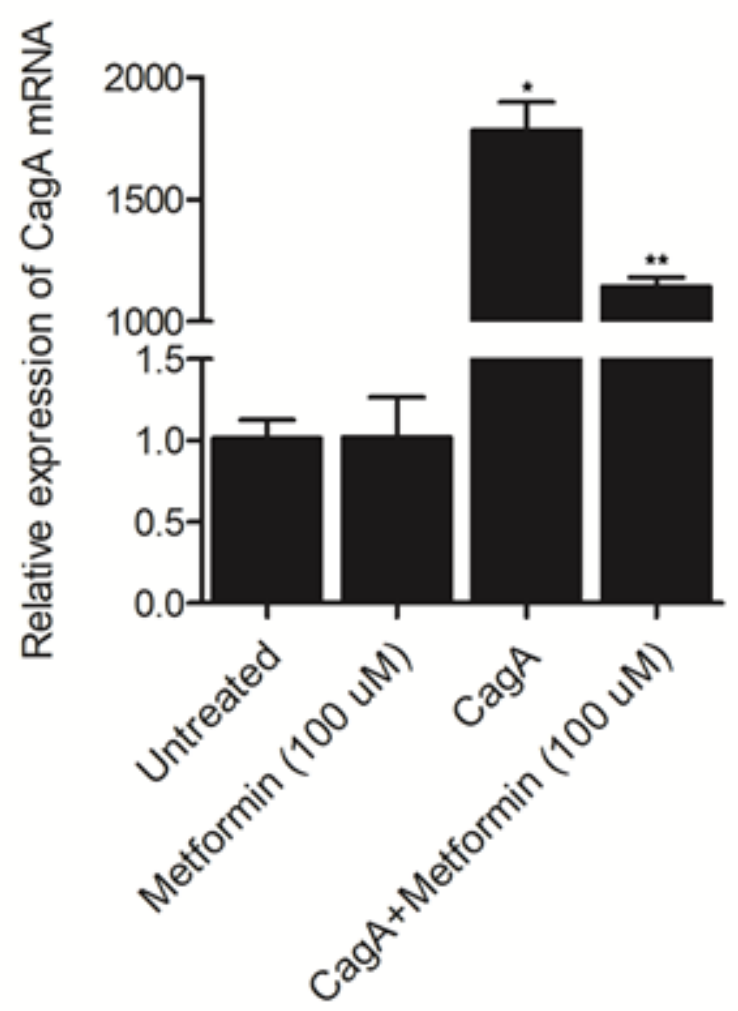

Figure 5

Metformin treatment decreased CagA induced up-regulation of CagA mRNA expression in HGC-27 cells (* $P$ value $<0.05$ vs. Untreated group; ${ }^{\star \star} P$ value $<0.05$, vs. CagA group).

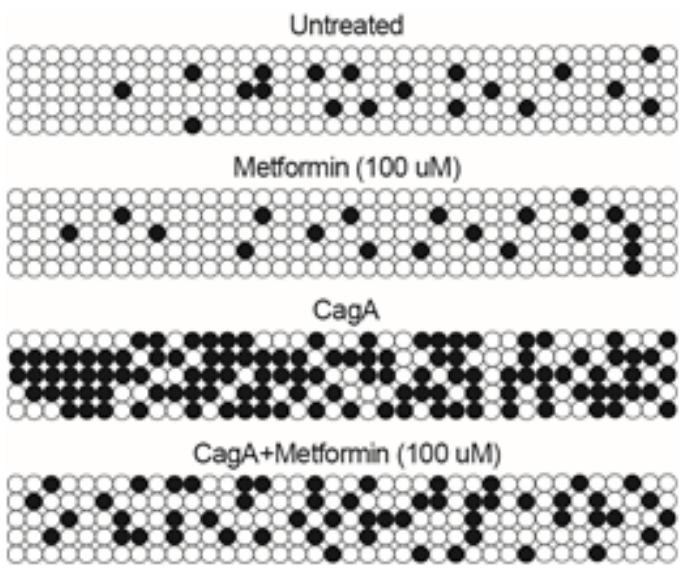

Figure 6

Bisulfite sequencing PCR analysis showed that metformin treatment reversed CagA-induced hypermethylation of PTEN promoter. 


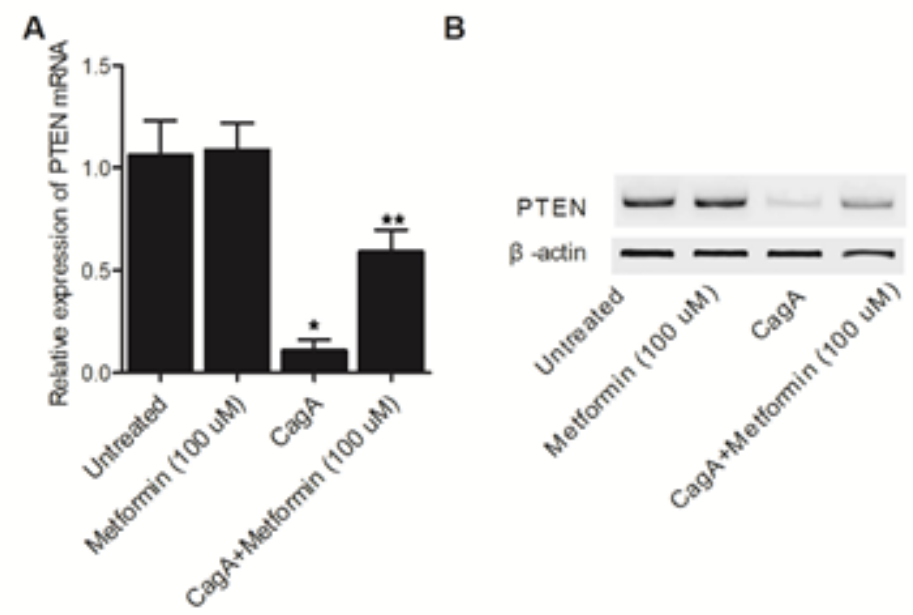

\section{Figure 7}

Metformin maintained CagA-induced decrease of PTEN expression in HGC-27 cells. A: CagA-induced decrease of PTEN mRNA expression was effectively restored by Metformin treatment ( ${ }^{P}$ value $<0.05 \mathrm{vs}$. Untreated group; $* \star P$ value $<0.05$, vs. CagA group). B: CagA-induced decrease of PTEN protein expression was effectively restored by Metformin treatment. 

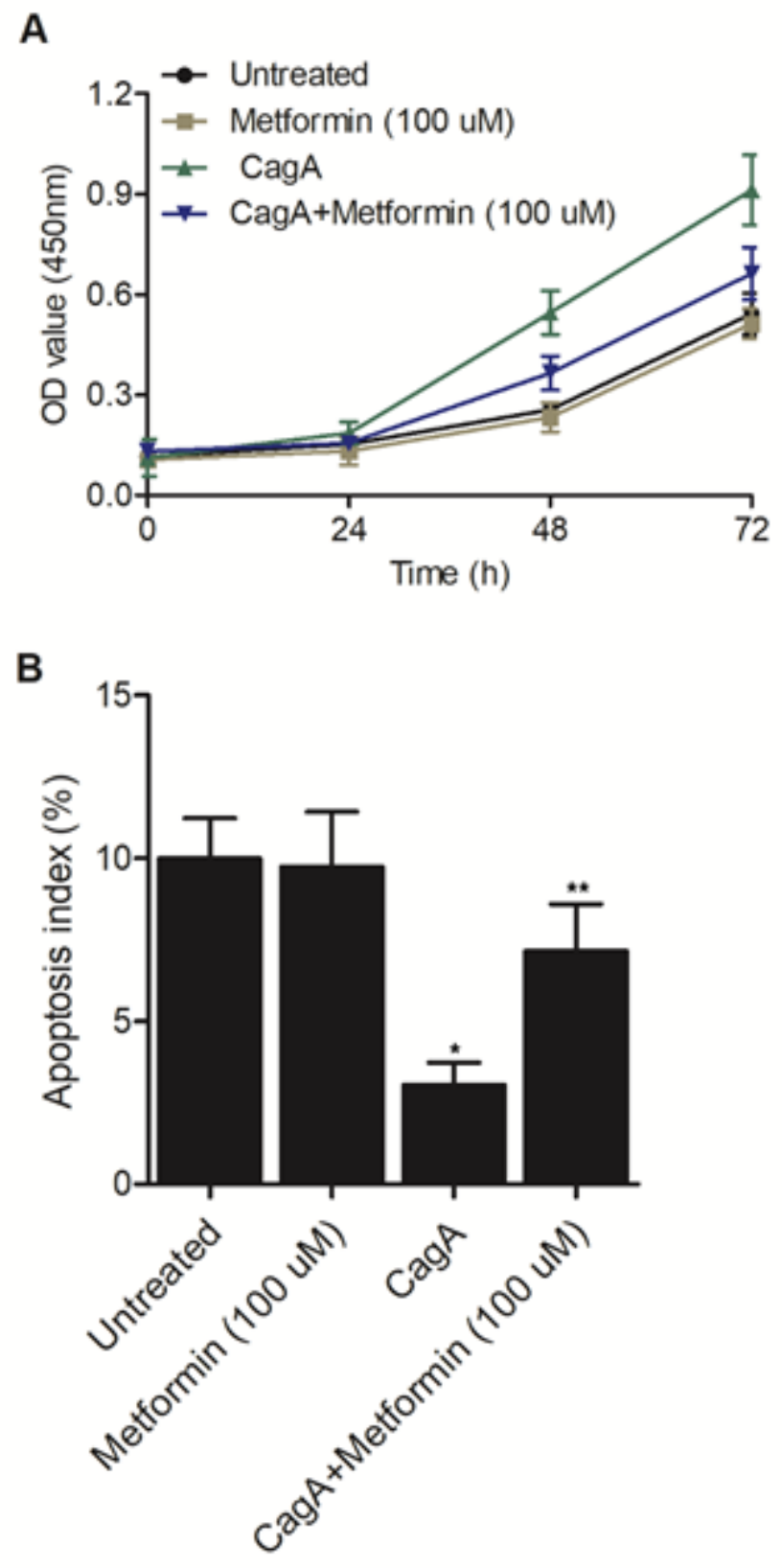

\section{Figure 8}

Metformin restored CagA-induced dysregulation of proliferation and apoptosis of HGC-27 cells. A: CagAinduced increase of HGC-27 cell proliferation was effectively restored by Metformin treatment. B: CagAinduced attenuation of $\mathrm{HGC}-27$ cell apoptosis was effectively restored by Metformin treatment (* $\mathrm{P}$ value $<0.05$ vs. Untreated group; ** $P$ value $<0.05$, vs. CagA group) 